\title{
Leisure-time physical activity in youth as a predictor of adult leisure physical activity among Japanese workers: a cross-sectional study
}

Hiroaki Itoh ${ }^{1}$, Fumihiko Kitamura ${ }^{1}$, Noriko Hagi ${ }^{2}$, Tomoe Mashiko ${ }^{3}$, Takehisa Matsukawa ${ }^{1}$ and Kazuhito Yokoyama ${ }^{1 *}$

\begin{abstract}
Background: Workers in Japan are not sufficiently active; however, it remains unclear how their leisure-time physical activity habits may be developed. This cross-sectional study investigated the relationship of age- and intensity-specific leisure-time physical activity in youth to adulthood leisure-time physical activity habits among Japanese workers.
\end{abstract}

Methods: In 2012, 968 workers (333 males and 635 females) from three companies and six hospitals in the Tokai region of Japan agreed to complete and submit a self-administered questionnaire. Intensity-specific leisure-time physical activity at ages 12 and 20 years was assessed retrospectively, and workers' current participation in regular leisure-time physical activity was assessed as an outcome measure. Multivariable-adjusted odds ratios (ORs) and 95\% confidence intervals ( $\mathrm{Cls}$ ) were calculated using logistic regression analysis.

Results: Mean ages for males and females were 40 and 37 years, respectively. Strenuous leisure-time physical activity at age 12 years was significantly positively associated with adulthood participation in leisure-time physical activity among male workers [adjusted OR $(95 \% \mathrm{Cl})=2.29(1.02,5.14)]$. Additionally, both strenuous and moderate physical activity at age 20 years was significantly positively associated with participation in regular leisure-time physical activity in adulthood among males and females.

Conclusions: Our results suggest that some leisure-time physical activity in youth may predict adult workers' participation in regular leisure-time physical activity in Japan. Encouragement of leisure-time physical activity in youth could therefore be an effective measure to develop adult leisure-time physical activity habits among workers.

Keywords: Physical activity, Exercise, Predictor, Determinant, Childhood, Adulthood

\section{Background}

Physical activity is associated with reduced risk of many chronic diseases [1] including cardiovascular diseases [2, 3], type 2 diabetes [4], and several cancers [5, 6], in addition to all-cause mortality [7]. Despite such apparent benefits of physical activity, a large proportion of adults in developed countries such as Japan do not participate in regular leisure-time physical activity. The National Health and

\footnotetext{
* Correspondence: kyokoya@juntendo.ac.jp

${ }^{1}$ Department of Epidemiology and Environmental Health, Juntendo

University Faculty of Medicine, 2-1-1 Hongo, Bunkyo-ku, Tokyo 113-8421,

Japan

Full list of author information is available at the end of the article
}

Nutrition Surveys in Japan for 1997, 2004, and 2009 revealed that $70-80 \%$ of the working generation (aged 20-59 years) were not sufficiently active (i.e., were exercising less than 30 min twice a week) [8]. Because workers in Japan may not have enough leisure time or be in the habit of participating in regular leisure-time physical activity, it remains unclear how their leisure-time physical activity habits could be developed.

In Western countries, a non-negligible number of studies suggest the possibility that physical activity in childhood and youth is associated with future physical activity [9]. Such a "carryover" may also be effective for building workers' leisure-time physical activity habits in Japan. 
However, previous studies have not reported consistent results [9-14]; therefore, further investigation is needed. Moreover, epidemiological evidence that considers specific age and intensity of leisure-time physical activity in youth and the relationship of these variables to leisure-time physical activity habits in adults is lacking, particularly in Asian countries. The Japanese mentality is unique and differs in potentially important ways from that of Western societies. Workaholism, obedience, tolerance and selfless devotion to country are typical Japanese tendencies that may influence workers' behavioral priorities and their responses to health promotion efforts. Because it is also unclear whether leisure-time physical activity in youth predicts leisure-time physical activity in adulthood among Japanese people, an epidemiological study is needed. In addition, the optimal intensity level of leisure-time physical activity at specific ages that is necessary to develop future leisure-time physical activity habits remains to be determined. For example, experience of strenuous leisuretime physical activity in youth may build an individual's physical strength and enable them to resume leisure-time physical activity in adulthood.

The purpose of the present study was to investigate, in a sample of Japanese workers, the associations between age- and intensity-specific leisure-time physical activity in youth and participation as an adult in regular leisuretime physical activity. Whereas most previous studies have examined the association between total activity in youth and total activity in adulthood [10], this study focused on leisure-time physical activity. This will provide further insights for promoting a more desirable physical activity strategy, because leisure-time activity is modifiable and controllable. Furthermore, health effects of leisure-time physical activity may differ from those of work-related physical activity. In fact, higher occupational physical activity has recently been shown to have acute and chronic adverse effects, such as increased risk of cardiovascular disease and all-cause mortality, particularly among men [15]. Therefore, our independent evaluation of leisure-time physical activity will be informative. We used ages 12 and 20 years as representative time points for leisure-time physical activity in youth, based on the following precedents. In previous studies conducted in Australia [10] and Canada [16] that tracked physical activity, the mean age at baseline was 12 years. In another tracking study conducted in Belgium [17], the mean ages of the male and female follow-up samples at baseline was 20 and 22 years, respectively.

Leisure-time physical activity is defined as "physical activity performed during exercise, recreation, or any time other than that associated with one's regular occupation, housework, or transportation" [18, 19], and as "primarily exercise or sports-related activities" [20]. "Exercise and other forms of physical training are types of recreational physical activity" [21]. Therefore, "leisure-time physical activity" may be synonymous with "exercise." These two terms were treated impartially in the present study.

\section{Methods \\ Participants}

In 2012, we conducted a cross-sectional study in three companies (railway, transport, and driving school) and six hospitals in the Tokai region of Japan. We distributed a paper questionnaire to nearly all employees (mean 92\%) at these workplaces. Of the 1,489 employees, 968 agreed to participate in the study (response rate 65\%) and submitted completed questionnaires. The questionnaire's instructions informed respondents that their participation was voluntary and that completing and returning the questionnaire would signify their agreement to participate. The sample comprised 333 males and 635 females (mean \pm SD of age were $40.0 \pm 10.6$ and $37.0 \pm 11.7$ years, respectively). Many of the participating hospital workers were nurses and practical nurses. The study procedure was approved in advance by the Institutional Review Board of the Juntendo University Faculty of Medicine, Tokyo, Japan (receipt number 813; approval letter number 2012057; May 21, 2012).

\section{Data collection using questionnaires}

The self-administered questionnaire collected information such as socio-demographic and anthropometric characteristics; lifestyle, including leisure-time physical activity; and medical history. Body mass index was calculated as weight in kilograms divided by the square of height in meters.

\section{Exposure assessment of youth leisure-time physical activity}

Intensity-specific leisure-time physical activity at 12 and 20 years was retrospectively assessed by the questionnaire. Details of this questionnaire have previously been described elsewhere [22]. With regard to intensity, the questionnaire first asked whether they participated in "strenuous leisure-time physical activity," with running, basketball, competitive swimming, and gymnastics provided as examples, as well as "moderate leisure-time physical activity" such as volleyball, softball, walking, and cycling. Participants were also asked to indicate how often they participated in the chosen activities, using the following six frequency categories: less than once per month, 1-3 days per month, 1-2 days per week, 3-4 days per week, 5-6 days per week, or every day of the week. For analyses, participation was transformed into a dichotomous variable: No (none) or Yes (which included "less than once per month," "1-3 days per month," "1-2 days per week," "3-4 days per week," "5-6 days per week," and "every day of the week"). This was because the number of workers with current participation in 
leisure-time physical activity in the present study was limited. In addition, history of participation in sports club activities, including organized school sports during preschool age, elementary school, junior high school, high school or higher professional school, and junior/ technical college or university was also assessed. Although sports club activities may partly overlap the above-mentioned leisure-time physical activities at ages 12 and 20 years, they were assessed separately.

\section{Outcome assessment of workers' leisure-time physical activity habits}

The sole outcome of the present study was leisure-time physical activity in adulthood. Here, "regular leisuretime physical activity" was defined as exercising at least twice a week for 30 min per session for more than 1 year. This definition was employed in the National Health and Nutrition Survey in Japan (Ministry of Health, Labour and Welfare of Japan).[8] Participants answered this single question with "yes" or "no."

\section{Statistical analysis}

All statistical analyses were performed with SAS software version 9.2 for Windows (SAS Institute Inc., Cary, NC, USA). One woman who did not provide her age, height, and weight, and reported an abnormally high physical activity level was excluded from the analysis. For comparisons of workers' characteristics according to current participation in leisure-time physical activity, we used Wilcoxon rank sum test for continuous variables and Fisher's exact probability test for categorical variables. Unconditional logistic regression analysis was performed to calculate multivariable-adjusted odds ratios (ORs) and 95\% confidence intervals (CIs) using the SAS LOGISTIC procedure. In this analysis, workers' current participation in leisure-time physical activity was entered as a dependent variable, while leisure-time physical activity in youth was entered as an independent variable. The ORs were adjusted for age (continuous variable) and education (dummy variable). We considered these variables to be potential confounders. Educational level was controlled because of a recent related finding [23]. However, we did not consider the number of holidays as a potential confounder based on causal diagrams [24]; indeed, the number of holidays availed by the workers in recent times would not affect their leisure-time physical activity habits in youth. All analyses were performed by sex, and observations with missing or disallowed values were not used for multivariable analyses (listwise case deletion). All p values and 95\% CIs were two-sided, and significance was accepted at $\mathrm{p}<0.05$. When we used leisure-time physical activity at age 20 years as an exposure variable, the participants under 20 years of age (four men and one woman) were excluded from the analysis.

\section{Results}

Table 1 shows participants' basic characteristics according to current participation in leisure-time physical activity by sex. There were no significant differences by current participation in leisure-time physical activity, with the exception of the number of holidays. Women participating in current leisure-time physical activity had more holidays than women without current participation in leisure-time physical activity, and women had more holidays than men.

Figure 1 shows the percentages of workers with current participation in regular leisure-time physical activity by age group. There was a higher proportion of participation in older age groups (50s and 60s).

Table 2 shows the ORs and 95\% CIs for workers' current participation in regular leisure-time physical activity by intensity levels of age-specific leisure-time physical activity. We found that strenuous leisure-time physical activity at age 12 years was significantly positively associated with current participation in leisuretime physical activity among male workers [adjusted OR $(95 \% \mathrm{CI})=2.29(1.02,5.14)]$. In contrast, female leisuretime physical activity at age 12 years was not significantly associated with adulthood participation in regular leisure-time physical activity. Moreover, strenuous and moderate leisure-time physical activity at age 20 years were also significantly positively associated with workers' current participation in regular leisure-time physical activity, and this held true for both males and females.

Table 3 shows ORs and 95\% CIs for workers' current participation in regular leisure-time physical activity by history of participation in sports club activities at a young age. Female participation in such activities during high school or higher professional school was significantly positively associated with their current participation in regular leisure-time physical activity [adjusted OR $(95 \% \mathrm{CI})=3.21(1.54,6.68)]$. In addition, female sports club activity in junior/technical college or university was also associated with participation in adulthood leisure-time physical activity. Point estimates for other ORs ranged from 1.16 to 2.18 , although they were statistically insignificant.

The direction and significance of the ORs in Tables 2 and 3 were unchanged after additionally adjusting for type of business (railway, transport, driving school, and hospital), night shift work, and the number of holidays (data not shown), with the exception of male sports club activity during high school or higher professional school [adjusted OR $(95 \% \mathrm{CI})=2.54(1.04,6.21)]$.

\section{Discussion}

Among Japanese workers, some leisure-time physical activities in youth were significantly positively associated with participation in regular leisure-time physical activity 
Table 1 Characteristics of study participants

\begin{tabular}{|c|c|c|c|c|c|c|}
\hline \multirow[b]{3}{*}{ Characteristics } & \multirow{2}{*}{\multicolumn{2}{|c|}{$\begin{array}{l}\text { Males } \\
\text { Current participation in regular leisure-time } \\
\text { physical activity }^{\mathrm{a}}\end{array}$}} & \multirow[b]{3}{*}{$p^{b}$} & \multirow{2}{*}{\multicolumn{2}{|c|}{$\begin{array}{l}\text { Females } \\
\text { Current participation in regular leisure-time } \\
\text { physical activity }^{\mathrm{a}}\end{array}$}} & \multirow[b]{3}{*}{$p^{b}$} \\
\hline & & & & & & \\
\hline & Yes & No & & Yes & No & \\
\hline N & 33 & 271 & & 42 & 534 & \\
\hline Age [years], mean $\pm \mathrm{SD}$ & $43.1 \pm 11.1$ & $39.8 \pm 10.4$ & 0.18 & $39.5 \pm 12.0$ & $36.5 \pm 11.3$ & 0.099 \\
\hline Body mass index $\left[\mathrm{kg} / \mathrm{m}^{2}\right]$, mean $\pm \mathrm{SD}$ & $23.2 \pm 2.9$ & $23.6 \pm 4.0$ & 0.78 & $23.6 \pm 4.0$ & $21.5 \pm 3.7$ & 0.75 \\
\hline Monthly overtime hours [hours], mean \pm SD & $27.7 \pm 26.1$ & $35.1 \pm 27.3$ & 0.16 & $6.4 \pm 5.2$ & $8.7 \pm 11.2$ & 0.80 \\
\hline Sleep duration [hours], mean \pm SD & $6.4 \pm 1.0$ & $6.3 \pm 1.0$ & 0.48 & $6.2 \pm 1.7$ & $6.4 \pm 1.1$ & 0.20 \\
\hline Number of holidays [days/month], mean \pm SD & $7.7 \pm 1.8$ & $7.1 \pm 2.0$ & 0.16 & $9.7 \pm 3.0$ & $9.0 \pm 2.2$ & 0.025 \\
\hline Length of service [years], mean \pm SD & $15.8 \pm 11.4$ & $15.7 \pm 10.4$ & 0.86 & $13.4 \pm 9.9$ & $12.5 \pm 10.1$ & 0.39 \\
\hline GHQ-12 score, mean \pm SD & $3.5 \pm 3.2$ & $3.8 \pm 3.4$ & 0.69 & $4.1 \pm 3.6$ & $4.0 \pm 3.3$ & 0.99 \\
\hline Educational level, n (\%) & & & 0.58 & & & 1.00 \\
\hline High school graduate & $10(32.3)$ & $80(31.6)$ & & $6(15.4)$ & $77(14.8)$ & \\
\hline Junior/technical college graduate & $8(25.8)$ & $48(19.0)$ & & $26(66.7)$ & $351(67.4)$ & \\
\hline University degree or higher & $13(41.9)$ & $125(49.4)$ & & $7(18.0)$ & $93(17.9)$ & \\
\hline Married, n (\%) & $22(66.7)$ & $186(69.9)$ & 0.69 & $22(55.0)$ & $263(49.6)$ & 0.62 \\
\hline Night-shift worker, n (\%) & $13(40.6)$ & $74(28.4)$ & 0.16 & $32(78.1)$ & $392(74.8)$ & 0.71 \\
\hline Current smoker, n (\%) & $7(21.9)$ & $106(40.0)$ & 0.054 & $8(19.5)$ & $56(10.7)$ & 0.12 \\
\hline Regular drinker, n (\%) & $14(43.8)$ & $125(46.8)$ & 0.85 & $11(26.8)$ & $111(21.3)$ & 0.43 \\
\hline $\begin{array}{l}\text { Any unusual item in the results of the latest } \\
\text { physical examination, } n(\%)\end{array}$ & $17(54.8)$ & $141(56.4)$ & 1.00 & $19(45.2)$ & $222(45.5)$ & 1.00 \\
\hline History of type 2 diabetes, n (\%) & $1(3.3)$ & $12(5.3)$ & 1.00 & $1(2.8)$ & $8(1.8)$ & 0.50 \\
\hline History of hypertension, n (\%) & $6(19.4)$ & $35(15.1)$ & 0.60 & $2(5.6)$ & $33(7.3)$ & 1.00 \\
\hline History of depression, n (\%) & $3(10.0)$ & $11(4.9)$ & 0.22 & $2(5.6)$ & $15(3.3)$ & 0.36 \\
\hline
\end{tabular}

Number of subjects varied across variables as a result of missing information GHQ-12 General Health Questionnaire 12-item scale [28], SD standard deviation ${ }^{a}$ Defined as exercising at least twice a week for 30 min per session for more than 1 year

${ }^{b}$ Wilcoxon rank sum test used for continuous variables and Fisher's exact probability test used for categorical variables

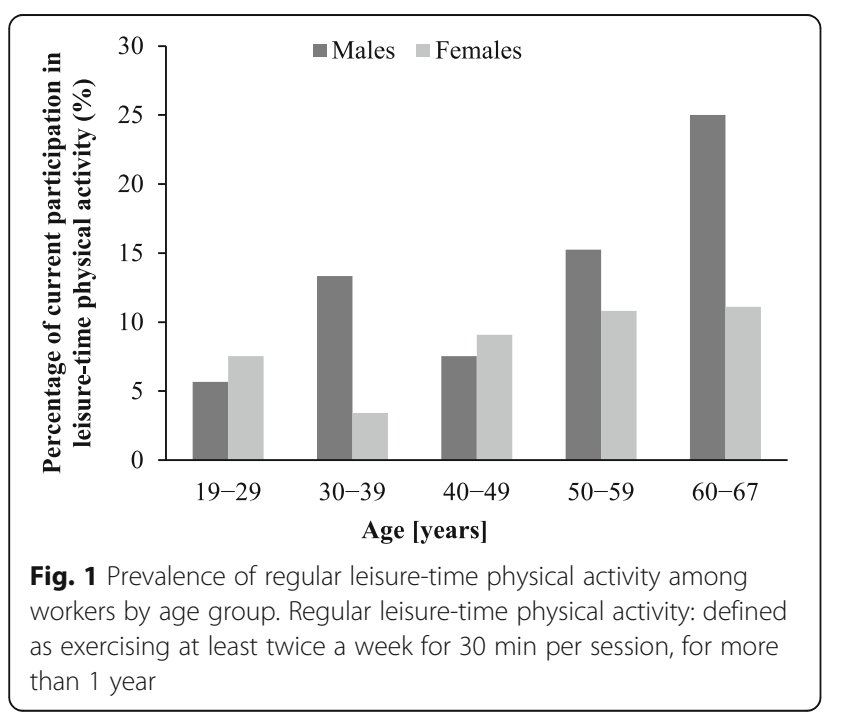

in adulthood. In particular, male strenuous leisure-time physical activity at 12 years old was positively associated with adulthood leisure-time physical activity. Strenuous and moderate leisure-time physical activities at age 20 years were also predictive of workers' current leisuretime physical activity behavior. Associations were evident and most were relatively strong in magnitude and consistent in direction. To our knowledge, this is the first study to investigate the association between leisuretime physical activity in youth and in adulthood among workers in an Asian country, also taking age- and intensityspecific activity into account. Although we only considered leisure-time physical activity, exposure in youth was a predictor of adult leisure-time physical activity in our Japanese sample. There is supportive evidence from a study in Australia reporting that childhood sport participation predicted adult physical activity, while total physical activity in childhood did not predict adult activity [10].

In this study, workers were distributed over a wide age range. Workers in older age groups tended to participate in regular leisure-time physical activity. This tendency is 
Table 2 Current participation in leisure-time physical activity according to intensity levels of age-specific leisure-time physical activity among Japanese workers

\begin{tabular}{|c|c|c|c|c|c|c|c|}
\hline \multirow{3}{*}{\multicolumn{2}{|c|}{$\begin{array}{l}\text { Leisure-time physical } \\
\text { activity }\end{array}$}} & \multicolumn{6}{|c|}{ Current participation in regular leisure-time physical activity $^{a}$} \\
\hline & & \multicolumn{2}{|c|}{ Males } & \multirow[b]{2}{*}{ Adjusted OR $(95 \% \mathrm{Cl})^{\mathrm{b}}$} & \multicolumn{2}{|c|}{ Females } & \multirow[b]{2}{*}{ Adjusted OR $(95 \% \mathrm{Cl})^{\mathrm{t}}$} \\
\hline & & $\overline{\text { Yes }}$ & $\overline{\mathrm{No}}$ & & $\overline{\text { Yes }}$ & $\overline{\mathrm{No}}$ & \\
\hline \multicolumn{8}{|c|}{ At age 12 years } \\
\hline \multirow[t]{2}{*}{ Strenuous ${ }^{c}$} & No & 15 & 158 & 1.00 (reference) & 26 & 357 & 1.00 (reference) \\
\hline & Yes & 18 & 109 & $2.29(1.02,5.14)$ & 15 & 169 & $1.40(0.69,2.81)$ \\
\hline \multirow[t]{2}{*}{ Moderate $^{d}$} & No & 12 & 119 & 1.00 (reference) & 20 & 286 & 1.00 (reference) \\
\hline & Yes & 18 & 144 & $1.27(0.56,2.86)$ & 22 & 225 & $1.50(0.77,2.92)$ \\
\hline \multicolumn{8}{|c|}{ At age 20 years } \\
\hline \multirow[t]{2}{*}{ Strenuous ${ }^{c}$} & No & 20 & 203 & 1.00 (reference) & 29 & 487 & 1.00 (reference) \\
\hline & Yes & 13 & 61 & $2.35(1.04,5.27)$ & 11 & 42 & $4.93(2.18,11.13)$ \\
\hline \multirow[t]{2}{*}{ Moderate $^{d}$} & No & 13 & 175 & 1.00 (reference) & 26 & 415 & 1.00 (reference) \\
\hline & Yes & 17 & 86 & $2.63(1.16,5.94)$ & 16 & 103 & $2.37(1.17,4.79)$ \\
\hline
\end{tabular}

Bold type indicates statistically significant values $(\mathrm{p}<0.05)$

$O R$ odds ratio, $\mathrm{Cl}$ confidence interval

${ }^{a}$ Defined as exercising at least twice a week for 30 min per session for more than 1 year

bunconditional logistic model adjusted for age (continuous) and education (high school, junior/technical college, university or higher)

${ }^{\mathrm{C} E x e m p l a r s ~ i n c l u d e ~ r u n n i n g, ~ p l a y i n g ~ b a s k e t b a l l, ~ s w i m m i n g ~ c o m p e t i t i v e l y, ~ o r ~ d o i n g ~ g y m n a s t i c s ~}$

dExemplars include playing leisure-time volleyball, playing softball, walking, or cycling

Table 3 Current participation in leisure-time physical activity according to history of participation in sports club activities among Japanese workers

\begin{tabular}{|c|c|c|c|c|c|c|}
\hline \multirow{3}{*}{$\begin{array}{l}\text { History of } \\
\text { participation } \\
\text { in sports } \\
\text { club } \\
\text { activities }^{\text {a }}\end{array}$} & \multicolumn{6}{|c|}{ Current participation in regular leisure-time physical activity ${ }^{b}$} \\
\hline & \multicolumn{2}{|c|}{ Males } & \multirow[b]{2}{*}{ Adjusted OR $(95 \% \mathrm{Cl})^{\mathrm{C}}$} & \multicolumn{2}{|c|}{ Females } & \multirow[b]{2}{*}{ Adjusted OR $(95 \% \mathrm{Cl})^{\mathrm{C}}$} \\
\hline & Yes & $\overline{\mathrm{No}}$ & & $\overline{Y e s}$ & $\overline{\mathrm{No}}$ & \\
\hline \multicolumn{7}{|c|}{ During preschool } \\
\hline No & 27 & 212 & 1.00 (reference) & 33 & 437 & 1.00 (reference) \\
\hline Yes & 6 & 59 & $1.42(0.50,4.07)$ & 9 & 92 & $1.70(0.70,4.19)$ \\
\hline \multicolumn{7}{|c|}{ During elementary school } \\
\hline No & 16 & 124 & 1.00 (reference) & 26 & 334 & 1.00 (reference) \\
\hline Yes & 17 & 147 & $1.17(0.49,2.81)$ & 16 & 196 & $1.32(0.64,2.74)$ \\
\hline \multicolumn{7}{|c|}{ During junior high school } \\
\hline No & 3 & 52 & 1.00 (reference) & 8 & 127 & 1.00 (reference) \\
\hline Yes & 30 & 217 & $2.03(0.58,7.07)$ & 34 & 405 & $1.24(0.56,2.78)$ \\
\hline \multicolumn{7}{|c|}{$\begin{array}{l}\text { During high school or } \\
\text { higher professional school }\end{array}$} \\
\hline No & 9 & 120 & 1.00 (reference) & 12 & 296 & 1.00 (reference) \\
\hline Yes & 22 & 146 & $2.18(0.95,5.03)$ & 28 & 225 & $3.21(1.54,6.68)$ \\
\hline \multicolumn{7}{|c|}{$\begin{array}{l}\text { During junior/technical } \\
\text { college or university }\end{array}$} \\
\hline No & 13 & 133 & 1.00 (reference) & 24 & 393 & 1.00 (reference) \\
\hline Yes & 6 & 55 & $1.16(0.41,3.31)$ & 11 & 67 & $2.48(1.10,5.61)$ \\
\hline
\end{tabular}

Bold type indicates statistically significant values $(p<0.05)$

$O R$ odds ratio, $\mathrm{Cl}$ confidence interval

ancluding both school clubs and sports clubs outside of school

${ }^{b}$ Defined as exercising at least twice a week for 30 min per session for more than 1 year

'Unconditional logistic model adjusted for age (continuous) and education (high school, junior/technical college, university or higher) 
consistent with that observed in Japan's National Health and Nutrition Survey [8]. Such change in behavior might be attributed in part to health consciousness and increased leisure time, given that those in older age groups no longer needed to care for young children.

Different intensities of leisure-time physical activity in youth were predictive of future leisure-time physical activity behavior. For males, strenuous leisure-time physical activity at age 12 years had a greater lingering effect than did moderate activity. Plausibly, children who engaged in strenuous leisure-time physical activity would gain physical strength more easily, enabling them to participate in future leisure-time physical activity. Additionally, because moderately intense leisure-time physical activity is often more accessible, safer, and more convenient, this level of activity at age 20 years may easily lead to lifelong participation. Our age- and intensity-specific analyses revealed that both strenuous and moderate intensity leisure-time physical activity at age 20 years was effective in developing future leisure-time physical activity habits. Thus, an ageand intensity-specific analysis can provide useful insights for leisure-time physical activity promotion strategies.

A sex difference in the results at age 12 was clearly observed. Such weaker associations in females may be attributed in part to major transitions in their life course, such as the transition from schooling to employment, from singlehood to marriage and having children, or experiencing unemployment [9]. Such events usually have different influences, particularly on continuous employment, for males and females in Japan. These findings regarding sex difference are supported by evidence from the majority of previous studies in Western countries. These studies also tend to show that childhood physical activity positively predicts adulthood physical activity in males, whereas about half of the associations are nonsignificant in females [9]. This tendency may be common in developed countries beyond the sphere of their residential area and local mindset.

Females' sports club activity during high school or above was significantly positively associated with regular participation in adult leisure-time physical activity. This was not the case for males, although the point estimate of the OR was high. The small sample size of the subgroup might have led to the null result. Furthermore, with regard to sports club activities prior to high school in both male and female participants, no significant associations were seen. It is known that physical activity in the distant past generally shows a weaker correlation with adulthood physical activity than does activity the near past [11]. Another possible explanation for the lack of a significant association between sports club activities at a younger age and participation in leisure-time physical activity in adulthood is that some students who did not participate in organized school sports might have participated in other leisure-time physical activities and physical education. Although a previous study conducted in the United States [13] reported that the frequencies of forced and encouraged exercise during the preteen years were inversely associated with adult physical activity, such an association was not observed in the present study. Therefore, sports club activity may also be recommended for young people in Japan.

From a descriptive perspective, Tables 2 and 3 show that most workers who had participated in leisure-time physical activity in youth were not currently participating in regular leisure-time physical activity. For example, of the 127 male workers who had participated in strenuous leisure-time physical activity at age 12 years, 109 did not exercise regularly in adulthood. This suggests that continuing or resuming leisure-time physical activity in adulthood might not have been easy for the participating workers. Further studies are needed to investigate the kind of work environment that supports their participation in leisure-time physical activity.

Major strengths of the present study were as follows. Our questionnaire for assessing exposure to leisure-time physical activity at a young age took into consideration the intensity, frequency and timing of leisure-time physical activity. Workers' current participation in regular leisure-time physical activity was clearly defined in terms of frequency and duration. Whereas most previous studies have examined the association between total activity in youth and in adulthood, the present study focused on leisure-time physical activity.

Several potential limitations of the study also warrant mention. First, we carried out multiple comparisons, which might have led to some false-positive results. However, we did not apply the Bonferroni correction because we considered this method too conservative. Second, owing to the cross-sectional nature of this investigation and self-reported measures of leisure-time physical activity habits in youth, we cannot completely rule out the possibility of error owing to recall bias. However, the reliability of long-term recall of participation in physical activity has been investigated in the United States and modest correlations have been reported [25]. Third, the response rate was suboptimal. However, the evidence for the relationship between low response rate and non-response bias is generally weak [26]; therefore, our moderate response rate may not necessarily indicate non-response bias. Fourth, the sample in the present study may not be representative of the general working population in Japan; therefore, our findings may not be applicable to a wide range of Japanese workers, although the observed associations were similar to those in previous studies. Although a disproportionate number of female participants (74.8\%) were night-shift workers, this type of work is common in modern society. In developed countries, about $20 \%$ of the working 
population is engaged in shift work [27]. More detailed information regarding the type of work may provide further insights when assessing these associations. In addition, our sample size was not large enough to allow dose-response analysis using the frequency of leisure-time physical activity in youth, as well as subgroup analyses by age groups. A larger study sample that enables such analyses should be considered for future studies. In addition, timing of assessment of leisure-time physical activity in youth at ages other than 12 and 20 years may be useful, as the effects of leisure-time physical activity at other ages might differ from those in transitional years such as ages 12 and 20 years.

\section{Conclusions}

In conclusion, our results suggest that certain aspects of leisure-time physical activity in youth may predict current participation in regular leisure-time physical activity in Japanese workers. Nurturing leisure-time physical activity in youth may be an effective measure to develop the future leisure-time physical activity habits of adult workers.

\section{Abbreviations}

Cl: Confidence interval; OR: Odds ratio

\section{Acknowledgments}

This work was funded by the Ministry of Education, Culture, Sports, Science and Technology (MEXT) - Supported Program for the Strategic Research Foundation at Private Universities, 2011-2015.

\section{Funding}

This work was funded by the Ministry of Education, Culture, Sports, Science and Technology (MEXT) - Supported Program for the Strategic Research Foundation at Private Universities, 2011-2015.

\section{Availability of data and materials}

Data cannot be shared due to privacy issues.

\begin{abstract}
Authors' contributions
$\mathrm{HI}$ developed the research question, contributed to preparing the questionnaire, conducting the literature survey, cleaning the data, performing the statistical analyses, interpreting the data, and preparing the manuscript. FK created the data collection plan, contributed to questionnaire preparation and helped to prepare the manuscript. NH and T Mashiko contributed to preparing the questionnaire, created the data collection plan, and conducted data collection. T Matsukawa prepared an application for the Institutional Review Board, contributed to questionnaire preparation, and helped to prepare the manuscript. KY contributed to questionnaire preparation, data interpretation, and the preparing of the manuscript. All authors approved the final manuscript.
\end{abstract}

\section{Competing interests}

The authors declare that they have no conflict of interest.

\section{Consent for publication}

Not applicable.

\section{Ethics approval and consent to participate}

All procedures performed in studies involving human participants were in accordance with the ethical standards of the institutional and/or national research committee and with the 1964 Helsinki declaration and its later amendments, or comparable ethical standards. Return of the questionnaire implied informed consent, although no written informed consent was obtained. The study procedure was approved in advance by the Institutional Review Board of the Juntendo University Faculty of Medicine, Tokyo, Japan (receipt number 813; approval letter number 2012057; May 21, 2012).

\section{Publisher's Note}

Springer Nature remains neutral with regard to jurisdictional claims in published maps and institutional affiliations.

\section{Author details}

${ }^{1}$ Department of Epidemiology and Environmental Health, Juntendo University Faculty of Medicine, 2-1-1 Hongo, Bunkyo-ku, Tokyo 113-8421, Japan. ${ }^{2}$ Yokkaichi Nursing and Medical Care University, Yokkaichi, Japan. ${ }^{3}$ Clinical Research Support Center, The University of Tokyo Hospital, Tokyo, Japan.

Received: 16 December 2016 Accepted: 22 March 2017

Published online: 07 April 2017

\section{References}

1. Warburton DE, Nicol CW, Bredin SS. Health benefits of physical activity: the evidence. CMAJ. 2006;174:801-9. doi:10.1503/cmaj.051351.

2. Bassuk SS, Manson JE. Epidemiological evidence for the role of physical activity in reducing risk of type 2 diabetes and cardiovascular disease. J Appl Physiol. 2005;99:1193-204. doi:10.1152/japplphysiol.00160.2005.

3. Bassuk SS, Manson JE. Physical activity and cardiovascular disease prevention in women: a review of the epidemiologic evidence. Nutr Metab Cardiovasc Dis. 2010;20:467-73. doi:10.1016/j.numecd.2009.12.015.

4. Jeon CY, Lokken RP, Hu FB, van Dam RM. Physical activity of moderate intensity and risk of type 2 diabetes: a systematic review. Diabetes Care. 2007:30:744-52. doi:10.2337/dc06-1842.

5. Inoue M, Yamamoto S, Kurahashi N, Iwasaki M, Sasazuki S, Tsugane S. Daily total physical activity level and total cancer risk in men and women: results from a large-scale population-based cohort study in Japan. Am J Epidemiol. 2008;168:391-403. doi:10.1093/aje/kwn146.

6. Suzuki R, Iwasaki M, Yamamoto S, Inoue M, Sasazuki S, Sawada N, Yamaji T, Shimazu T, Tsugane S. Leisure-time physical activity and breast cancer risk defined by estrogen and progesterone receptor status-the Japan Public Health Center-based Prospective Study. Prev Med. 2011;52:227-33. doi:10. 1016/j.ypmed.2011.01.016.

7. Samitz G, Egger M, Zwahlen M. Domains of physical activity and all-cause mortality: systematic review and dose-response meta-analysis of cohort studies. Int J Epidemiol. 2011;40:1382-400. doi:10.1093/ije/dyr112.

8. Miyachi M. Measures of physical activity and exercise for health promotion by the Ministry of Health, Labour and Welfare. J Phys Fitness Sports Med. 2012;1:467-72. doi:10.7600/jpfsm.1.467.

9. Telama R. Tracking of physical activity from childhood to adulthood: a review. Obes Facts. 2009;2:187-95. doi:10.1159/000222244.

10. Cleland V, Dwyer T, Venn A. Which domains of childhood physical activity predict physical activity in adulthood? A 20-year prospective tracking study. Br J Sports Med. 2012;46:595-602. doi:10.1136/bjsports-2011-090508.

11. Suzuki K. What past sports experiences are necessary to establish lifelong exercise habits? : Past sports experiences before adulthood for establishing lifelong exercise habits (in Japanese). Jap J Hum Growth Developm Res. 2009:41:1-9. doi:10.5332/hatsuhatsu.2009.41_1.

12. Telama R, Yang X, Leskinen E, Kankaanpaa A, Hirvensalo M, Tammelin T, Viikari JS, Raitakari OT. Tracking of physical activity from early childhood through youth into adulthood. Med Sci Sports Exerc. 2014;46:955-62. doi:10. 1249/mss.0000000000000181.

13. Taylor WC, Blair SN, Cummings SS, Wun CC, Malina RM. Childhood and adolescent physical activity patterns and adult physical activity. Med Sci Sports Exerc. 1999;31:118-23.

14. Smith L, Gardner B, Aggio D, Hamer M. Association between participation in outdoor play and sport at 10 years old with physical activity in adulthood. Prev Med. 2015;74:31-5. doi:10.1016/j.ypmed.2015.02.004.

15. Holtermann A, Marott JL, Gyntelberg F, Sogaard K, Suadicani P, Mortensen OS, Prescott E, Schnohr P. Occupational and leisure time physical activity: risk of all-cause mortality and myocardial infarction in the Copenhagen city heart study. A prospective cohort study BMJ Open. 2012;2:e000556. doi:10. 1136/bmjopen-2011-000556.

16. Herman KM, Craig CL, Gauvin L, Katzmarzyk PT. Tracking of obesity and physical activity from childhood to adulthood: the physical activity longitudinal study. Int J Pediatr Obes. 2009;4:281-8. doi:10.3109/17477160802596171.

17. De Bourdeaudhuij I, Sallis J, Vandelanotte C. Tracking and explanation of physical activity in young adults over a 7-year period. Res Q Exerc Sport. 2002;73:376-85. doi:10.1080/02701367.2002.10609037. 
18. Lin YP, Huang YH, Lu FH, Wu JS, Chang CJ, Yang YC. Non-leisure time physical activity is an independent predictor of longevity for a Taiwanese elderly population: an eight-year follow-up study. BMC Public Health. 2011;11:428. doi:10.1186/1471-2458-11-428.

19. Kandula NR, Lauderdale DS. Leisure time, non-leisure time, and occupational physical activity in Asian Americans. Ann Epidemiol. 2005;15:257-65. doi:10.1016/j.annepidem.2004.06.006.

20. US Centers for Disease Control and Prevention (CDC). Prevalence of physical activity, including lifestyle activities among adults-United States, 2000-2001. MMWR Morb Mortal Wkly Rep. 2003;52:764-9.

21. World Cancer Research Fund / American Institute of Cancer Research. Food, nutrition, physical activity and the prevention of cancer: a global perspective. Washington: AICR; 2007.

22. Suzuki R, Iwasaki M, Kasuga Y, Yokoyama S, Onuma H, Nishimura H, Kusama R, Shimazu T, Tsugane S. Leisure-time physical activity and breast cancer risk by hormone receptor status: effective life periods and exercise intensity. Cancer Causes Control. 2010;21:1787-98. doi:10.1007/s10552-010-9605-7.

23. Mäkinen TE, Borodulin K, Tammelin TH, Rahkonen O, Laatikainen T, Prättälä R. The effects of adolescence sports and exercise on adulthood leisure-time physical activity in educational groups. Int J Behav Nutr Phys Act. 2010;7:27. doi:10.1186/1479-5868-7-27.

24. Greenland S, Pearl J, Robins JM. Causal diagrams for epidemiologic research. Epidemiology. 1999;10:37-48

25. Blair SN, Dowda M, Pate RR, Kronenfeld J, Howe Jr HG, Parker G, Blair A Fridinger $F$. Reliability of long-term recall of participation in physical activity by middle-aged men and women. Am J Epidemiol. 1991;133:266-75.

26. Choung R, Locke III GR, Schleck C, Ziegenfuss J, Beebe T, Zinsmeister A, Talley N. A low response rate does not necessarily indicate non-response bias in gastroenterology survey research: a population-based study. J Public Health. 2013;21:87-95. doi:10.1007/s10389-012-0513-z

27. Härmä M. Shift work among women-a century-old health issue in occupational health. Scand J Work Environ Health. 2008;34:1-3. doi:10.5271/sjweh.1188.

28. Goldberg DP. The detection of psychiatric illness by questionnaire: A technique for the identification and assessment of non-psychotic psychiatric illness, Maudsley Monograph, vol. 21. London: Oxford University Press; 1972.

\section{Submit your next manuscript to BioMed Central and we will help you at every step:}

- We accept pre-submission inquiries

- Our selector tool helps you to find the most relevant journal

- We provide round the clock customer support

- Convenient online submission

- Thorough peer review

- Inclusion in PubMed and all major indexing services

- Maximum visibility for your research

Submit your manuscript at www.biomedcentral.com/submit 